\title{
OVELHAS APRISIONADAS: A CONVERSÃO RELIGIOSA E O "REBANHO DO SENHOR" NAS PRISÕES
}

\author{
Edileuza Santana Lobo \\ Universidade Estadual do Rio de Janeiro*
}

Resumo: A partir da metáfora bíblica do pastor e suas ovelhas, apresento uma breve análise da atuação dos evangélicos em unidades prisionais do Complexo Frei Caneca no Rio de Janeiro. Meu objetivo é demonstrar o crescimento das igrejas evangélicas nas prisões, onde procuro identificar o universo prisional como campo fértil para o proselitismo religioso. Apresento também o relato de um culto na prisão, onde procuro perceber como se dá a recepção da crença evangélica pelos presidiários e a elaboração dessa crença no cotidiano da prisão.

Palavras-chave: conversão, evangélicos, prisão, religião.

Keywords: conversion, evengelics, prision, religion.

A conversão religiosa no ambiente prisional é um tema que, aos poucos, ganhou visibilidade e chama atenção pela curiosidade que desperta, principalmente em se tratando de presidiários. O fenômeno da conversão de presos, se por um lado tem levantado críticas sobre a veracidade da conversão, se eles não estariam "se escondendo atrás da Bíblia” (Scheliga, [s.d.]), por outro tem sido compreendido como iniciativa que produz efeito na vida do preso, uma vez que os agentes religiosos, no contato diário com eles e conhecendo as limitações da sobrevivência na prisão, acabam ultrapassando a fronteira religiosa, atuando também em outras dimensóes sociais das prisóes. Não são

Doutoranda em Ciências Sociais. 
poucas as igrejas e instituições religiosas que ocupam funções do Estado no que se refere a suprir necessidades materiais dos internos, gerando, assim, uma parceria informal com os diretores das unidades prisionais.

Para compreender a prisão como campo religioso na concepção de Bourdieu (1998), pretendo analisar a atuação dos evangélicos nas prisões, cujos efeitos principais são a conversão dos detentos e a reprodução da crença no ambiente prisional. A finalidade proselitista é indiscutível na atuação desses agentes. Entretanto, sem ter pretensão de oferecer respostas, pretendo aqui colocar alguns elementos para pensar os efeitos sociais que essa atuação produz. Até que ponto a conversão religiosa pode contribuir para inserção social do indivíduo encarcerado? Qual o significado de ser crente na prisão? Até que ponto a conversão é uma estratégia de sobrevivência? Nesse texto, não tratarei especificamente do pentecostalismo, porque nas unidades em que pesquiso existe também expressiva atuação de outras igrejas evangélicas não pentecostais, como a Igreja Batista e Igreja Metodista. Optei por utilizar o termo "evangélico", conceito que abrange os pentecostais e os evangélicos tradicionais. Devo ressaltar, no entanto, que o predomínio dos pentecostais é notório e mesmo os evangélicos tradicionais, no contexto prisional, realizam cultos de estilo pentecostal apenas no aspecto formal, sem enfatizar exorcismo ou a prática da glossolalia, características reconhecidas dos grupos pentecostais.

\section{CRESCIMENTO PENTECOSTAL NAS PRISÕES}

O crescimento da presença de evangélicos nas prisões, iniciado na década de 1990, coincide com o auge do crescimento pentecostal já analisado por alguns estudiosos. ${ }^{1}$ Anteriormente, as atividades religiosas nas prisões se restringiam à Igreja Católica e algumas denominações evangélicas, dentre elas a

1 Sobre crescimento pentecostal e mudanças no campo religioso brasileiro, ver Mariano (2001) e Sanchis (1997); no caso específico do Rio de Janeiro, ver Fernandes (1998). 
Assembléia de Deus e a Igreja Batista. Conforme depoimento de alguns agentes religiosos, a presença dos evangélicos naquela ocasiāo era fruto de iniciativas isoladas, o que leva a concluir que o investimento no presidiário como alvo de proselitismo religioso é recente, fruto da iniciativa dos pentecostais no sentido de alcançar setores sociais marginalizados.

Com o impulso do crescimento pentecostal, configurou-se nas prisóes um campo religioso, marcado pela atuação de representantes de diversas igrejas evangélicas que escolheram os presídios como espaço privilegiado para a reprodução de suas crenças. O sucesso desse empreendimento se dá em grande parte pelas condições que o sistema penitenciário oferece ao indivíduo condenado pela justiça para o cumprimento da sua pena. Superlotação de prisóes, condições precárias de sobrevivência, lentidão da justiça no andamento dos processos, demonstrando, assim, violação de direitos da parte das autoridades que deveriam garantir esses direitos. De certa forma, quando tentam atender necessidades materiais dos presidiários e solucionar pendências jurídicas, as igrejas estão cumprindo funções que seriam atribuições do Estado. Não se deve esquecer, no entanto, que são estrategicamente interessantes para as igrejas tais atribuiçōes.

\section{AGENTES RELIGIOSOS, CONVERSÃO E ASSISTÊNCIA SOCIAL}

A presença expressiva dos evangélicos nas prisóes causa um certo mal estar aos demais segmentos religiosos que prestam assistência naqueles espaços, principalmente da parte dos católicos, que acusam os evangélicos de constranger os presos, forçando-os à conversão. Por outro lado, percebo que os diretores das unidades penais são simpáticos à presença dos evangélicos. Em alguns casos isso se explica quando o diretor também compartilha a fé evangélica, como acontece em alguns presídios do Rio; em outros, pela ajuda que as igrejas e grupos religiosos vêm dando aos diretores, no sentido de viabilizar, do ponto de vista material, a concretização de alguns projetos realizados nas unidades. Assim, as igrejas evangélicas têm atuado em parceria na administração das unidades prisionais e, de certa forma, têm contribuído para a administração de conflitos naqueles locais. 
A assistência social é estratégica no sentido de alcançar o objetivo dos agentes religiosos, a conversão do detento. Isso dá visibilidade aos evangélicos, cuja presença na "distribuição dos bens de salvação" aos presidiários é notória. Um dos efeitos da atuação desses grupos é a transformação no espaço físico das prisōes, com a organização das "celas evangélicas", resultado da articulação do agente religioso com a administração da unidade. Os detentos, agora "nascidos de novo" (Fernandes, 1998), procuram se distinguir da "massa carcerária" 2 e tentam estabelecer uma "comunidade de irmãos" dentro da prisão. Nesse caso, a conversão representa uma ruptura com sua história pessoal. ${ }^{3}$ Os novos convertidos começam a assimilar uma nova ética, cujos valores vão se consolidando a partir da distinção no ambiente carcerário. Os agentes religiosos defendem com veemência a segregação dos convertidos num espaço só para eles, pois, segundo declararam, isso promove a comunhão entre os novos irmãos, a consolidação da fé e contribui para uma "cadeia calma", resultado da mudança de comportamento dos detentos, conforme declarou uma missionária que entrevistei.

Houve uma reivindicação daqueles que se convertiam e de nós, enquanto capelães, para que houvesse espaço para aqueles que querem seguir a palavra, e aqueles que não querem continuassem no seu convívio de bebida, de prostituição, do que quiserem. Mas aqueles que querem, que tivessem seu espaço para mudança, para busca de santificação, e foi aceito então.

Os agentes religiosos cuidam para que os presos que manifestam o desejo de seguir a religião se comportem de acordo com o padrão evangélico.

2 Ramalho (1979) define massa como o conjunto dos presos ou dos criminosos Segundo este autor, "entidade" e "trato" são termos-chave para compreender o significado de massa como algo distinto dos presos e dos criminosos e pode ser explicado como conjunto de regras postulado e seguido por eles. Embora, do ponto de vista da lei, possam ser considerados criminosos, do ponto de vista das leis da massa nem todos o são, ou seja, não fazem parte da vida do crime.

3 Ver Aubrée (1996). 
Esperam que seus novos discípulos dêem "bom testemunho" dentro da prisão e que se esforcem para "levar outros presos ao conhecimento de Cristo", 4 que reproduzam o novo ethos que adotaram. Os novos convertidos tornamse multiplicadores da nova religião à qual aderiram e se organizam em função de proporcionar ambiente favorável à expansão da fé. O Presídio Hélio Gomes $^{5}$ que visitei em 2002 e onde trabalho atualmente como professora na escola ali localizada, ${ }^{6}$ possui uma população carcerária de 920 detentos, em média. Quando lá estive pela primeira vez, contava com oito celas evangélicas. Atualmente, segundo revelou a missionária que ainda atua naquele espaço, existem cerca de dez celas. Cada uma comporta uma média de 25 a 30 homens; nota-se que não é desprezível o número de convertidos naquela prisão. A missionária contou que naquele presídio presta serviços de aconselhamento e coordena as atividades religiosas com os "dirigentes de celas", e disse também que tem recebido muito apoio do diretor e funcionários, e, quando organizaram um centro cultural, colocaram seu nome para homenageá-la. Disse ainda que, além da assistência religiosa, desenvolve alguns projetos relacionados à informática e "cursos profissionalizantes".

A Penitenciária Lemos de Brito tem capacidade para 598 detentos e, segundo o pastor Vicente Paulo, responsável pela assistência religiosa naquela unidade, a Igreja Evangélica Assembléia de Deus possui 125 internos cadas-

${ }^{4} \mathrm{Na}$ Penitenciária Lemos de Brito tive oportunidade de encontrar algumas vezes o Grupo de Visitação e Evangelismo da Penitenciária Lemos de Brito, formado por detentos, geralmente três ou quatro, que visitam as dependências da unidade, todos com a Bíblia embaixo do braço, distribuindo folhetos de evangelização.

5 O Presídio Hélio Gomes é uma unidade de regime fechado e ali cumprem pena os detentos que não estão vinculados à facção ou que estão no "seguro"; se afirma que em outra unidade este detento poderia correr risco, caso pertença à facção criminosa diferente daquela presente nessa unidade.

${ }^{6}$ No Complexo Frei Caneca existem duas escolas com classes de alfabetização, ensino fundamental e médio: o Colégio Rubem Braga, com sede no Presídio Milton Dias Moreira e anexo ao Presídio Hélio Gomes, e o Colégio Mario Quintana, com sede na Penitenciária Lemos de Brito e anexo ao Presídio Pedrolino de Oliveira. 
trados como membros da igreja, sem contar aqueles que têm "simpatia pelo evangelho", mas ainda não se decidiram; estes freqüentam os cultos como assistentes. O pastor declarou que coordena uma equipe de 30 agentes religiosos que trabalham de domingo a domingo, e que, além da Lemos de Brito, dão assistência também no Pedrolino de Oliveira, ${ }^{7}$ Milton Dias Moreira e algumas unidades do Complexo de Bangu. Disse que sua igreja atua na formação religiosa, cultural e profissional, e que desenvolve alguns projetos em parceria com empresas. Um dos projetos, Eliminando o Analfabetismo, atua em parceria com a Alfalit, uma empresa que trabalha com professores através da Associação das Igrejas Evangélicas Atuantes nos Presídios no Estado do Rio de Janeiro (Assiaperj), "organização não governamental” criada pelo pastor Vicente Paulo. Disse que implantou curso de teologia na prisão, com duração de dois anos, e que no Pedrolino de Oliveira, onde está atuando há 12 anos, já formou quatro turmas. Informou ainda que implantou o curso profissionalizante de elétrica e eletrônica, enfatizando que é um curso reconhecido e que encaminha para emprego quando o preso cumpre sua pena.

\section{COMO OS AGENTES RELIGIOSOS PERCEBEM O PRESO}

Segundo a declaração da missionária Adenice Barreto ([s.d.]), "cada um deles, que sair da cadeia como nova criatura, será um ladrão a menos, um traficante a menos, um divulgador do amor de Deus a mais".

A questão do pecado, que norteia o discurso evangélico de modo geral, no universo prisional tem suas proporções aumentadas. O crime que o indivíduo cometeu é explicado como resultado de uma vida imersa no pecado e controlada pelo demônio (Birman, 1997; Mariz, 1997): para deixar a vida criminosa, os agentes religiosos afirmam que só nascendo de novo, tornando-se "nova criatura". Nessa percepção, isso só acontece quando o indivíduo

\footnotetext{
${ }^{7}$ Mais conhecido como P. O. Localizado no Complexo Frei Caneca, é destinado a ex-policiais militares e civis, bombeiros e agentes penitenciários que cumprem pena separados dos presos de outras unidades, para evitar confrontos.
} 
aceita Jesus e se converte. Além disso, dizem os agentes religiosos, somam-se aspectos socioeconômicos decorrentes da imoralidade, violência, prostituição e vícios, que levam à degradação social, condição essa propícia para a ação do "mal" e que, segundo os evangélicos, só pode ser mudada pelo poder de Jesus Cristo e do evangelho.

Para serem bem sucedidos na pregação religiosa, os evangélicos que entrevistei informaram que o agente religioso, para atuar junto aos presos, precisa conhecer o perfil daqueles que serão objeto de sua ação. Na maioria das vezes, descrevem os presidiários como pessoas infelizes que entraram para o crime como forma de sobrevivência, e que na infância foram crianças abandonadas e tiveram uma criação em ambiente de violência. Dizem que, à primeira vista, são inseguros e desconfiados e que a maioria nunca experimentou sentimentos de amor e segurança. Geralmente trazem sentimentos de culpa pelo crime que cometeram e acabam tornando-se vítimas de confusões religiosas, porque ficam expostos aos ensinos que não condizem "com as verdades expressas na palavra de Deus". Vale ressaltar que esse perfil descrito pelo agente religioso é fruto do senso comum e de experiência do contato freqüiente desses agentes com os internos.

Uma missionária contou que procura trabalhar a auto-estima dos presos, que seu objetivo é levá-los a compreender que, apesar dos erros que cometeram contra a sociedade e contra o próprio Deus, o amor de Deus não acaba. Essa idéia de auto-estima pode ser pensada através da noção de "indivíduo como valor”, desenvolvida por Dumont (1993); é nessa perspectiva que se dá o discurso religioso. No contexto prisional, o indivíduo privado da liberdade e de outros acessos básicos para sua sobrevivência entra num processo de deterioração de sua identidade, conforme análise de Goffman (1996). De certa forma, a condição em que o preso se encontra o torna vulnerável aos apelos externos, principalmente aqueles que tocam sua individualidade. Além de não ser tão culpado quanto pensava, já que o crime praticado é conseqüência da ação do demônio. $\mathrm{O}$ discurso do amor de Deus, somado à ajuda material, contribui para amenizar o sofrimento na prisão e proporciona a sensação de auto-estima, produzindo um novo significado na vida de muitos presidiários. 


\section{O REBANHO NA PRISÃO}

Nas unidades prisionais onde tenho acompanhado o desenvolvimento das atividades religiosas os evangélicos promovem cultos e realizam outras funções ligadas à igreja diariamente. Estudos bíblicos, reuniôes de oração, palestras e ensaios musicais, muitos ficam tão envolvidos com as atividades da igreja que chegam até a reclamar da falta de tempo dentro da cadeia. Estão sempre "muito ocupados", e encontram dificuldades para conciliar "o trabalho da igreja" com estudos ou outras atividades laborativas.

$\mathrm{Na}$ Penitenciária Lemos de Brito e Presídio Pedrolino de Oliveira foi implantado o curso de teologia, para formação de multiplicadores da fé. Isso resulta na formação de um "corpo de especialistas religiosos" (Bourdieu, 2001) constituído de "irmãos encarcerados”. Estes acabam se tornando os líderes da congregação local e cuidam para que as funções religiosas sejam cumpridas e que a igreja esteja diariamente à disposição dos que quiserem participar. Percebe-se, nesses espaços, uma dinâmica religiosa produzida pelos evangélicos, o que de certa forma ajuda a passar o tempo da cadeia. Essa dinâmica é gerada pelo movimento freqüente de internos ocupados em suas funções na igreja, o que proporciona naqueles espaços a visibilidade do grupo. $\mathrm{O}$ visitante que entrar na Lemos de Brito não demora a perceber que algum tipo de atividade de caráter religioso está sendo realizada naquela unidade, como ensaios de grupos musicais, grupo de visitação, já citado anteriormente, "cultos ao ar livre", 8 reuniōes de oração, ou seja, o "rebanho de Cristo" está organizado para atrair novas ovelhas.

Nesse sentido, os agentes religiosos atuam como coordenadores de uma equipe que já está exercendo atividade efetiva, e sua presença não é condição

${ }^{8}$ Os cultos ao "ar livre", nas igrejas evangélicas extramuros, geralmente acontecem em ocasiões especiais, como comemorações ou visita de algum pastor ilustre. São cultos rápidos em praças próximas à igreja, onde um grupo, levando aparelhagem de som potente, procura chamar atenção dos moradores do entorno para o culto que acontecerá na igreja. Os evangélicos da Penitenciária Lemos de Brito também fazem esse tipo de atividade, no pátio da unidade, com objetivo de alcançar o maior número de presidiários. 
para a realização ou não dos cultos. Cabe aos "dirigentes de cultos" internos da prisão fazer cumprir os compromissos religiosos, supervisionados pelos agentes religiosos que são os mediadores entre a "congregação" no interior da prisão e as igrejas extramuros.

\section{RELATO DE UM CULTO NA PRISÃO}

Este é um relato de um "culto festivo" no Presídio Hélio Gomes, e acredito que pode ajudar a compreender o fenômeno religioso nas prisões. $\mathrm{Na}$ ocasião fui acompanhando a missionária Adenice, da Igreja Batista. Essa foi minha primeira visita ao presídio para assistir a uma atividade religiosa. Essa missionária é responsável pela assistência religiosa dos evangélicos naquela unidade, e estava à frente da cerimônia que iria ser realizada. Disse que era um culto especial, por isso festivo, porque na ocasião haveria celebração de batismos. Na prática, significava que o "rebanho do Senhor naquele presídio seria acrescido de mais algumas ovelhas".

Chegamos ao presídio às $14 \mathrm{~h}$. Na portaria, entregamos nossa carteira de identidade e o funcionário conferiu a listagem que já havia ali das pessoas que entrariam com a missionária. Tivemos nossa bolsa revistada, depois passamos por uma porta detectora de metais. $\mathrm{O}$ agente então abriu o pesado portão, com cadeados enormes, e chegamos num espaço aberto, onde se vê a parte administrativa do presídio. À frente, outro portão pesado, dois agentes penitenciários abriram a tranca e entramos em direção ao pátio interno da unidade. $\mathrm{O}$ estado de degradação do ambiente é grande e me causou muito desconforto. Chegando ao pátio, me surpreendi com o número de detentos "soltos" que ali se encontravam. Segundo nos informaram, havia uns 150 homens naquele pátio. Percebi naquele momento que também partilhava do sentimento, cristalizado no imaginário coletivo, de que a proximidade com aqueles "monstros" nos colocava em situação de risco. Essa primeira visita também me serviu para relativizar esse preconceito. Passado o primeiro impacto, percebi que para o contexto da prisão estavam "bem vestidos", havia um certo cuidado com vestuário para estar ali, participando do evento. Muitos talvez estivessem usando a melhor roupa, muitos usavam calça jeans, 
camisa de tecido por dentro da calça com cinto, sapato ou tênis. Pareciam descontraídos, grupos conversando animadamente, alguns ensaiando as músicas que seriam apresentadas, outros organizando o espaço de culto, enfim, não fosse pelo espaço físico deteriorado e pela visão que a parte superior do prédio proporcionava - com braços e pernas para fora das grades, numa cena desordenada que causava desconforto, e do outro lado da parte superior, uma guarita com um policial armado em atitude alerta -, dava até para esquecer que estávamos no interior de uma prisão.

Um púlpito colocado à frente e alguns detentos com instrumentos musicais, como órgão elétrico, violão e pandeiro, improvisavam um templo evangélico. $\mathrm{O}$ culto teve início com a missionária declarando que os batismos daquela tarde representavam a ação de Deus naquele lugar, "restaurando vidas, tirando-as das mãos de Satanás”. Seu discurso, intercalado com apresentações musicais dos detentos, ressaltava a todo instante o poder de Deus para resgatar vidas. Naquela tarde, havia também um pastor, "convidado especial", que estaria conduzindo os rituais do batismo. Ao tomar a palavra, o pastor convocou os candidatos ao batismo para preencherem uma ficha, por meio da qual seriam cadastrados como membros da Igreja Batista. Alertou para o compromisso que os internos deveriam ter com a igreja daquele dia em diante. As fichas deveriam ser preenchidas antes da cerimônia e as questôes a serem respondidas eram: nome, endereço, número de identidade, telefone, data da conversão e que religião seguia antes da conversão. Percebi um certo desconforto de alguns em fornecer informaçôes pessoais, um deles chegou a perguntar se alguém iria na sua casa e outro, se poderia freqüentar outra igreja caso desejasse. Enquanto aqueles que iam se batizar preenchiam as fichas, o culto seguia com apresentaçóes musicais pelos detentos, alternadas pelas pregações e leitura de textos bíblicos pelo pastor. Os ouvintes sentados nos bancos de cimento ouviam atentamente o que o pastor dizia, sempre respondendo com aleluias e glória a Deus. Terminada a pregação, todos levantaram e foram para o fundo do pátio, onde havia uma piscina plástica de dois mil litros cheia de água, para os detentos se batizarem. Chegara o momento em que os "novos crentes", conduzidos pelo pastor, dariam a sua "profissão de fé pública, o sim para Jesus”. Depois, o pastor os fazia mergulhar "nas águas", concretizando-se, ali, o ritual do "novo nascimento". 
Ao ser batizado, o detento se torna membro da igreja que patrocinou o seu batismo. A suposta conversão de presidiários às igrejas evangélicas proporciona ao preso a inserção no grupo, ou seja, na metáfora religiosa significa que a ovelha encontrou seu rebanho. $\mathrm{O}$ detento passa a fazer parte de uma comunidade de fiéis, constituindo, assim, uma relação de compromisso entre o preso e a igreja, mediada pelo agente religioso. Como os agentes religiosos afirmam, o indivíduo entra para o crime por falta de perspectivas e, nesse sentido, o apoio material e afetivo é fundamental para a auto-estima do preso, e contribui também para atenuar as dificuldades vividas na prisão.

\section{CONSIDERAÇÕES FINAIS}

Ao longo do texto, procurei apresentar uma abordagem exploratória e compreensiva da dinâmica religiosa produzida pela presença das igrejas evangélicas nas prisões. Meu ponto de partida foi o crescimento das igrejas pentecostais e a atuação dos agentes religiosos no universo prisional. Tentei demonstrar a configuração de um campo religioso nas prisões a partir da noção analisada por Bourdieu (1998, p. 64), e nesse "campo de disputa" os evangélicos estão ganhando visibilidade e contam com o apoio dos diretores dos presídios. Segundo afirmação recorrente, a religião acalma o preso e os diretores não querem problemas na sua administração. Reconheço também que a relação entre agentes religiosos e os diretores dos presídios poderia ser mais explorada, o que farei em outro texto.

A percepção do preso pelos agentes e o relato do culto na prisão foram resultado de entrevistas com agentes religiosos de diferentes confissões, como Igreja Universal do Reino de Deus, Igreja Batista, Igreja Assembléia de Deus e Igreja Católica e, também, de algumas visitas às unidades prisionais do Complexo Frei Caneca, para acompanhar os agentes religiosos nas atividades ali desenvolvidas. Essa pesquisa resultou na minha dissertação de mestrado (Lobo, 2002).

Provavelmente, muitos presos "estão se escondendo atrás da Bíblia"; por outro lado, também é possível que a conversão religiosa venha a trazer sentido para a vida daquelas pessoas ou até contribuir para que o cumprimento da 
pena seja menos sofrido. Atualmente, as opções religiosas nas prisões são muitas, o "rebanho do senhor" continua crescendo, as "ovelhas desgarradas", também.

\section{REFERÊNCIAS}

AUBRÉE, Marion. Tempo, história e Nação (o curto-circuito dos pentecostais). Religião e Sociedade: Pentecostes e Nova Era: fronteiras e passagens, v. 17, n. 1-2, p. 77-88, ago. 1996.

BARRETO, Adenice. Clínica de Capelania Prisional: estratégia de evangelização em presídios. [s.d.]. Mimeografado.

BIRMAN, P. Males e malefícios no discurso pentecostal. In: BIRMAN, P.; NOVAES, R.; CRESPO, S.(Org.). O mal à brasileira. Rio de Janeiro: Eduerj, 1997. p. 62-79.

BOURDIEU, P. O poder simbólico. Rio de Janeiro: Bertrand Brasil, 1998. . A economia das trocas simbólicas. São Paulo: Perspectiva, 2001.

DUMONT, Louis. $O$ individualismo: uma perspectiva antropológica da ideologia moderna. Rio de Janeiro: Rocco, 1993.

FERNANDES, Rubem César. Novo nascimento: os evangélicos em casa, na igreja e na política. Rio de Janeiro: Mauad, 1998.

GOFFMAN, Erving. Manicômios, prisões e conventos. São Paulo. Perspectiva, 1996.

LOBO, Edileuza Santana. "Igrejas atrás das grades": um estudo sobre a atuação de católicos e evangélicos no sistema penitenciário do Rio de Janeiro. Dissertação (Mestrado em Sociologia)-IFCS, Universidade Federal do Rio de Janeiro, rio de Janeiro, 2002.

MARIANO, Ricardo. Análise sociológica do crescimento pentecostal no Brasil. Tese (Doutorado em Sociologia)-FFLCH, Universidade de São Paulo, São Paulo, 2001. 
MARIZ,Cecília L. O Demônio e os pentecostais no Brasil. In: BIRMAN, P.; NOVAES, R.; CRESPO, S.(Org.). O mal à brasileira. Rio de Janeiro: Eduerj, 1997. p. 45-61.

RAMALHO, José Ricardo. O mundo do crime: a ordem pelo avesso. Rio de Janeiro: Graal, 1979.

SANCHIS, Pierre. O campo religioso contemporâneo no Brasil. In: ORO, Ari Pedro; STEIL, Carlos Alberto (Org.). Globalização e religiāo. Petrópolis: Vozes, 1997. p. 103-115.

SCHELIGA, Eva Lenita. "Ele está se escondendo atrás da Bíblia": a conversão religiosa ao pentecostalismo em unidades penais. [s.d.]. Mimeografado. 